\title{
Development of $\mathrm{La}^{3+}$ Doped $\mathrm{CeO}_{2}$ Thick Film Humidity Sensors
}

\author{
Chunjie Wang, ${ }^{1}$ Aihua Zhang, ${ }^{1}$ and Hamid Reza Karimi ${ }^{2}$ \\ ${ }^{1}$ College of Engineering, Bohai University, Jinzhou 121013, China \\ ${ }^{2}$ Department of Engineering, Faculty of Engineering and Science, The University of Agder, 4898 Grimstad, Norway \\ Correspondence should be addressed to Chunjie Wang; cjwang@foxmail.com
}

Received 2 January 2014; Accepted 18 January 2014; Published 3 March 2014

Academic Editor: Ming Liu

Copyright (C) 2014 Chunjie Wang et al. This is an open access article distributed under the Creative Commons Attribution License, which permits unrestricted use, distribution, and reproduction in any medium, provided the original work is properly cited.

\begin{abstract}
The humidity sensitive characteristics of the sensor fabricated from $10 \mathrm{~mol} \% \mathrm{La}_{2} \mathrm{O}_{3}$ doped $\mathrm{CeO}_{2}$ nanopowders with particle size $17.26 \mathrm{~nm}$ synthesized via hydrothermal method were investigated at different frequencies. It was found that the sensor shows high humidity sensitivity, rapid response-recovery characteristics, and narrow hysteresis loop at $100 \mathrm{~Hz}$ in the relative humidity range from $11 \%$ to $95 \%$. The impedance of the sensor decreases by about five orders of magnitude as relative humidity increases. The maximum humidity hysteresis is about $6 \% \mathrm{RH}$, and the response and recovery time is 12 and $13 \mathrm{~s}$, respectively. These results indicate that the nanosized $\mathrm{La}_{2} \mathrm{O}_{3}$ doped $\mathrm{CeO}_{2}$ powder has potential application as high-performance humidity sensor.
\end{abstract}

\section{Introduction}

Due to the recognized importance of vapor concentration, humidity sensors as an important chemical sensor have been widely used in medicine, agriculture, and environment monitoring $[1,2]$. The suitable humidity sensing materials should possess some characteristics including high sensitivity, good chemical and physical stability, rapid response and recovery time, and low hysteresis $[3,4]$. In the past few years, humidity sensors are developed towards miniaturization and integration with the development of technology. To improve the performance of the humidity sensor, it is quite essential to improve the sensing materials with high sensitivity and reliability.

Generally, the materials for humidity sensors are mainly organic polymer films and porous ceramic films. In the case of organic polymers, however, the main disadvantages are the low operation temperature, poor physical and chemical stability, and weak mechanical strength. For porous ceramic humidity sensors with porous structured films, the major problems are the dull response and recovery time. Among the various candidate materials of sensors, $\mathrm{CeO}_{2}$ becomes heatedly discussed topic in recent years, which can be attributed to its large diffusion coefficient for oxygen vacancy and good corrosion resistance to corrosive gases $\left(\mathrm{Cl}_{2}, \mathrm{SO}_{2}\right.$, and $\mathrm{NO}$ ) [5]. Due to the longer response and recovery time, however, the sensor fabricated from pure $\mathrm{CeO}_{2}$ cannot meet the increasing requirements.

Owing to the remarkable physicochemical activity, rare earth materials have been widely used to improve the performance of the functional materials. In the past decade, considerable efforts have been paid to the investigation of rare earth doped sensing materials. Li et al. studied $\mathrm{La}^{3+} / \mathrm{Ce}^{3+}$ doped $\mathrm{TiO}_{2}-\mathrm{SnO}_{2}$ thin films as humidity sensors [6]. Shimizu et al. devoted their work to the phase separation and leaching techniques of $\mathrm{La}_{2} \mathrm{O}_{3}-\mathrm{TiO}_{2}$ porous thick film [7]. Anbia and Fard reported the humidity sensing properties of Ce-doped $\mathrm{ZnO}$ thin film, which shows high humidity sensitivity, repaid response and recovery, good repeatability, and narrow hysteresis loop [8]. Unfortunately, to the best of our knowledge, the performance of humidity sensors based on $\mathrm{La}^{3+}$ doped with $\mathrm{CeO}_{2}$ has not been reported. In our previous work, the nanosized $\mathrm{La}_{2} \mathrm{Ce}_{2} \mathrm{O}_{7}$ powders have been synthesized via hydrothermal method, the products show higher specific surface area, smaller particle size for nanoparticles, and a porous networking microstructure for calcined compacted body, which have a potential application as sensors [9].

To obtain fine nanopowders, various methods have been proposed in recent years. Due to the advantages which related to the homogeneous nucleation processes and fine grain size, hydrothermal method is considered as one of the most promising techniques for the manufacture of nanopowders. 


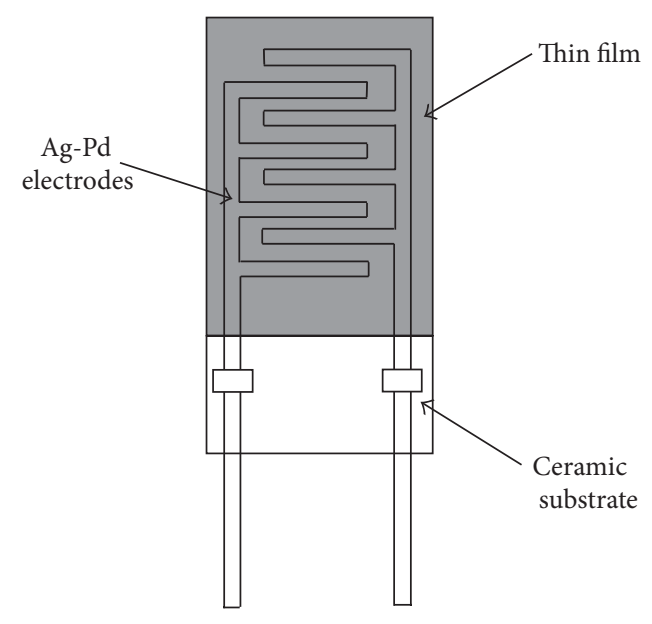

FIgURE 1: The schematic diagram of sensor structure.

In this paper, nanosized $10 \mathrm{~mol} \% \mathrm{La}^{3+}$ doped $\mathrm{CeO}_{2}$ powders were prepared by hydrothermal method; the humidity sensing properties, response and recovery time, and hysteresis characteristic of the corresponding sensor were investigated in the relative humidity range from $11 \%$ to $95 \%$ with various frequencies at room temperature. The main purpose of this study is expected to enhance the humidity sensing performance of the composite films and broaden the database of sensor materials.

\section{Experimental}

Nanopowders of $10 \mathrm{~mol} \% \mathrm{La}_{2} \mathrm{O}_{3}$ doped $\mathrm{CeO}_{2}$ were synthesized via the conventional hydrothermal method. $\mathrm{La}_{2} \mathrm{O}_{3}$ and $\mathrm{Ce}\left(\mathrm{NO}_{3}\right)_{3} \cdot 6 \mathrm{H}_{2} \mathrm{O}(99.99 \%$, Shanghai Chemicals Ltd.) were used as the starting materials. Firstly, appropriate amounts of $\mathrm{La}_{2} \mathrm{O}_{3}$ were dissolved in concentrated nitric acid and then mixed with a stoichiometric $\mathrm{Ce}\left(\mathrm{NO}_{3}\right)_{3} \cdot 6 \mathrm{H}_{2} \mathrm{O}$ aqueous solution under vigorous stirring. The final molar concentration of the solution is $0.1 \mathrm{M}$. A certain amount of PEG (2 wt.\%, Shanghai Chemicals Ltd.) as surfactant was then added into the mixed solution. The $\mathrm{pH}$ value of the solution was adjusted to 7 by $\mathrm{NaOH}(2 \mathrm{M})$. The nanopowders were obtained by hydrothermal treatment for the suspension at $180^{\circ} \mathrm{C}$ for $24 \mathrm{~h}$ in a Teflon autoclave. The precipitates were then filtered and washed with distilled water and ethanol six times and dried at $70^{\circ} \mathrm{C}$ for $12 \mathrm{~h}$.

In order to investigate the structure of the products, the powders were calcined at different temperatures for $5 \mathrm{~h}$ with a heating rate of $5^{\circ} \mathrm{C} \cdot \mathrm{min}^{-1}$ and then cooled down naturally. The crystalline phases of nanocrystalline powders were identified by powder X-ray diffraction (XRD, Bruker D8 Focus powder X-ray diffractometer) using $\mathrm{Cu} \mathrm{K} \alpha$ radiation $(\lambda=1.5406 \AA)$ with a scanning rate of $5^{\circ} \mathrm{C} \cdot \mathrm{min}^{-1}$. The operation voltage and current were maintained at $40 \mathrm{kV}$ and $40 \mathrm{~mA}$, respectively.

The mean particle size of powders $(D)$ was determined by Scherrer's equation [10]:

$$
D=\frac{\lambda K}{\beta \cos \theta},
$$

where $\lambda$ is the wavelength of the X-ray radiation, $\theta$ is the diffraction angle, $K$ is a constant (0.89), and $\beta$ is the corrected full-width half maximum (FWHM). The Gaussian-Gaussian relationship was also used for the correction of the instrument [10]:

$$
\beta^{2}=B^{2}-b^{2},
$$

where FWHM of the sample is represented by $B$ and $b$ is for the standard width of reference silicon sample.

FT-Raman spectra were recorded on a Thermo Nicolet 960 instrument with an excitation wavelength of $1064 \mathrm{~nm}$, and the wave number range is from 100 to $900 \mathrm{~cm}^{-1}$. The specific surface area $\left(S_{\mathrm{BET}}\right)$ was determined by BrunauerEmmet-Teller (BET) equation [11, 12] with a Micromeritics ASAP2020 instrument. The morphology and the particle size of the sample were investigated by a field emission scanning electron microscope (SEM, Hitachi S-4800) and a Philips TFF20 electron transmission microscope (TEM).

Figure 1 is the schematic diagram of the humidity sensor. In order to fabricate the humidity sensor, the as-synthesized nanopowders were dispersed in ethanol with magnetic stirring for $30 \mathrm{~min}$. The mixed solution was then dropped onto a ceramic substrate $(6 \mathrm{~cm} \times 3 \mathrm{~cm}, 0.5 \mathrm{~cm}$ in thick $)$ to form a film with a thickness of about $10 \mu \mathrm{m}$. Furthermore, the humidity sensors were annealed at $180^{\circ} \mathrm{C}$ for $1 \mathrm{~h}$ and then dried naturally. The characteristic curves of humidity sensitivity were obtained from a ZL-5 model LCR analyzer (Shanghai, China). In our study, the voltage was fixed at $1 \mathrm{~V}$, and the frequencies were varied from $20 \mathrm{~Hz}$ to $100 \mathrm{KHz}$. The humidity of laboratory atmosphere was $25 \% \mathrm{RH}$ controlled by an automatic drier. The humidity environments were obtained by $\mathrm{LiCl}, \mathrm{MgCl}_{2}, \mathrm{Mg}\left(\mathrm{NO}_{3}\right)_{3}, \mathrm{NaCl}, \mathrm{KCl}$, and $\mathrm{KNO}_{3}$ saturated salt solutions, and the corresponding $\mathrm{RH}$ values were $11,33,54,75,85$, and $95 \% \mathrm{RH}$, respectively.

\section{Results and Discussion}

The crystal structure of the as-obtained and sintered powders of $10 \mathrm{~mol} \% \mathrm{La}_{2} \mathrm{O}_{3}$ doped $\mathrm{CeO}_{2}$ (10 LC) was examined by XRD, as shown in Figure 2(a). It can be noted that all XRD patterns match well with the standard cubic fluorite phase of $\mathrm{CeO}_{2}$ [JCPDS 43-1002]. The diffraction peaks at about $28.1^{\circ}$, $32.6^{\circ}, 46.8^{\circ}$, and $55.7^{\circ}$ can be indexed to the (111), (200), (220), and (311) reflections of cubic fluorite structure, respectively. The diffraction peaks become sharper and narrower with the increasing temperature which can be attributed to the growth of crystal. In addition, the average crystallite size and specific surface area were also investigated. The average crystallite size and the specific surface area of as-synthesized $10 \mathrm{LC}$ are $17.26 \mathrm{~nm}$ and $126.54 \mathrm{~m}^{2} \cdot \mathrm{g}^{-1}$, respectively. The crystal size was calculated by Scherrer's equation as mentioned in Experimental section.

Raman scattering was also utilized to carefully identify the phase structure in the wave number range of 100 $900 \mathrm{~cm}^{-1}$. Figure 2(b) represents the Raman spectra of assynthesized $10 \mathrm{~mol} \% \mathrm{La}_{2} \mathrm{O}_{3}$ doped $\mathrm{CeO}_{2}$ and pure $\mathrm{CeO}_{2}$ 


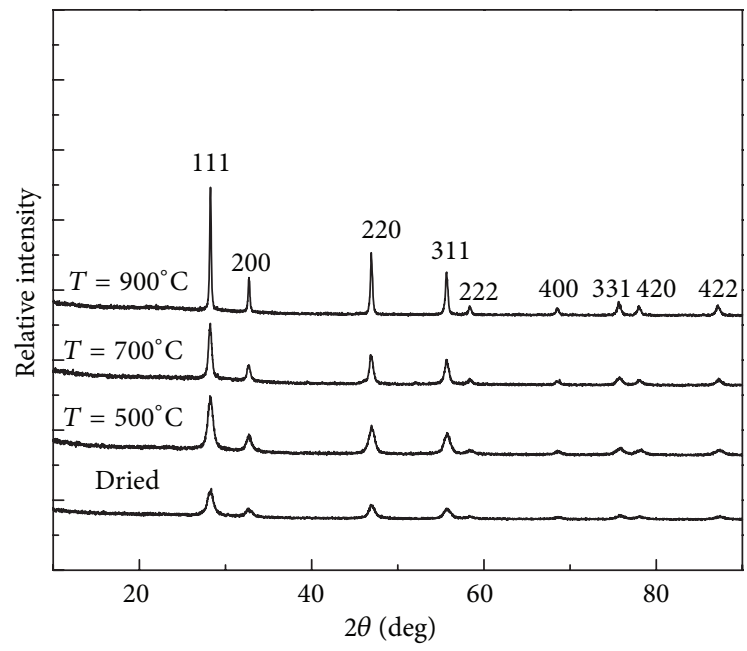

(a)

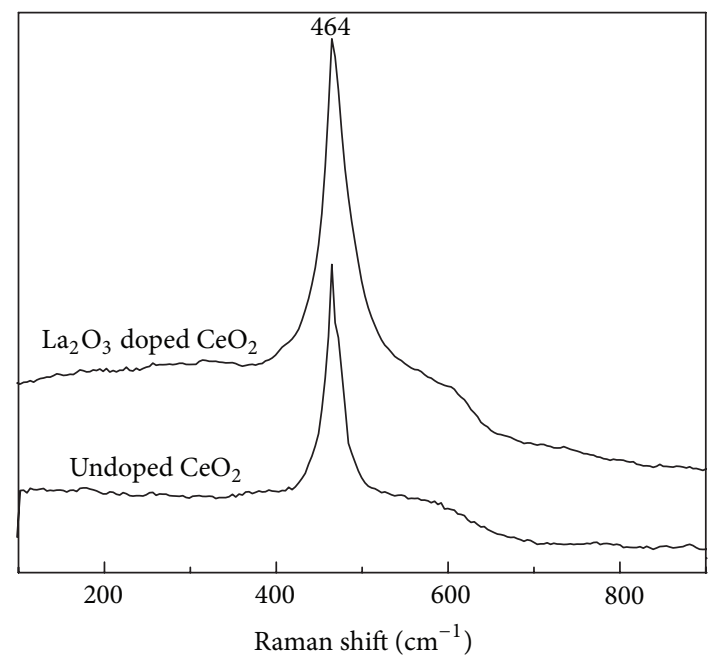

(b)

Figure 2: XRD patterns of 10 mol\% $\mathrm{La}_{2} \mathrm{O}_{3}$ doped $\mathrm{CeO}_{2}$ calcined at different temperatures (a); Raman spectra of $10 \mathrm{~mol}_{2} \mathrm{La}_{2} \mathrm{O}_{3}$ doped $\mathrm{CeO}_{2}$ and undoped $\mathrm{CeO}_{2}$ (b).

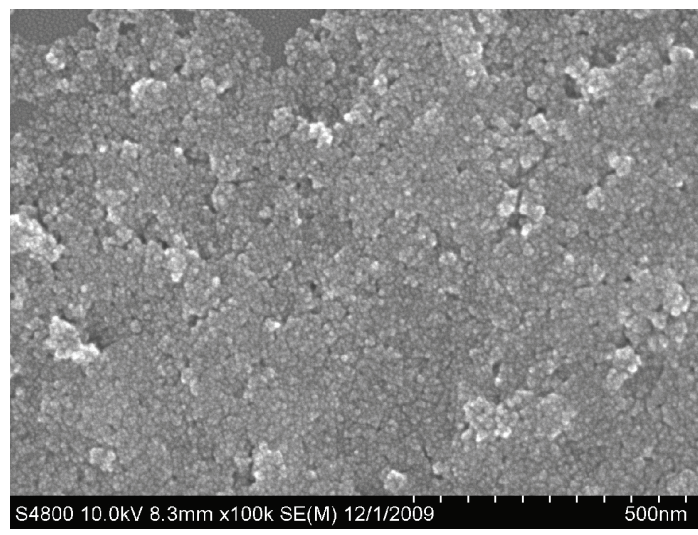

FIGURE 3: SEM micrograph of as-synthesized $10 \mathrm{~mol} \% \mathrm{La}_{2} \mathrm{O}_{3}$ doped $\mathrm{CeO}_{2}$.

nanocrystal. Careful investigation of the spectra revealed a detailed structure of cubic type. For both samples, the main peak at about $464 \mathrm{~cm}^{-1}$ corresponds to the $\mathrm{F}_{2 \mathrm{~g}}$ Raman band of a cubic fluorite structure. Obviously, for $10 \mathrm{LC}$, this band is broader and more asymmetric than that of pure $\mathrm{CeO}_{2}$, which is the common feature of the effect of rare earth-doping on the $\mathrm{F}_{2 \mathrm{~g}}$ band $[13,14]$. Moreover, a small shoulder appeared at about $600 \mathrm{~cm}^{-1}$ which can be assigned as a longitudinal optical mode arises [15].

The morphology and particle size of the synthesized materials were further investigated by SEM and TEM. Figure 3 is the typical SEM image of as-prepared $10 \mathrm{LC}$ nanopowders. It is easy to find that the mean particle sizes are in the range of $15 \sim 20 \mathrm{~nm}$. The agglomerates of nanopowders

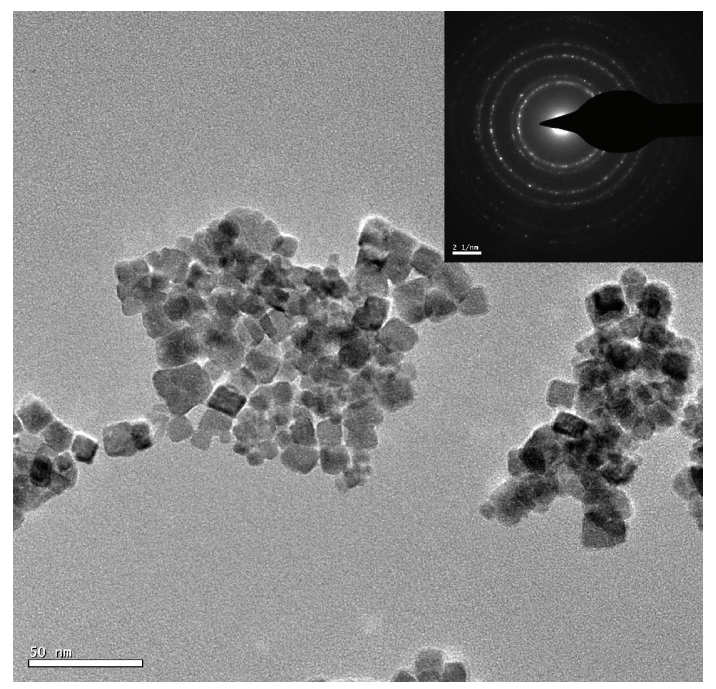

FIgUre 4: Typical TEM image of as-prepared $10 \mathrm{~mol} \% \mathrm{La}_{2} \mathrm{O}_{3}$ doped $\mathrm{CeO}_{2}$.

may be due to the uncontrolled coagulation during the process of preparation [16]. Typical TEM and SAED images of assynthesis $10 \mathrm{LC}$ are shown in Figure 4. From the figure, it can be clearly noted that the as-synthesized powders are mainly composed of monodispersed square particles with an average particle size of $17.63 \mathrm{~nm}$. The determined mean particle size is the average value of 20 particles selected randomly. The average particle size obtained from TEM pattern is consistent with that calculated from Scherrer's equation. Furthermore, the individual bright diffraction spots (inset in Figure 4) indicate that the particles are polycrystals. 


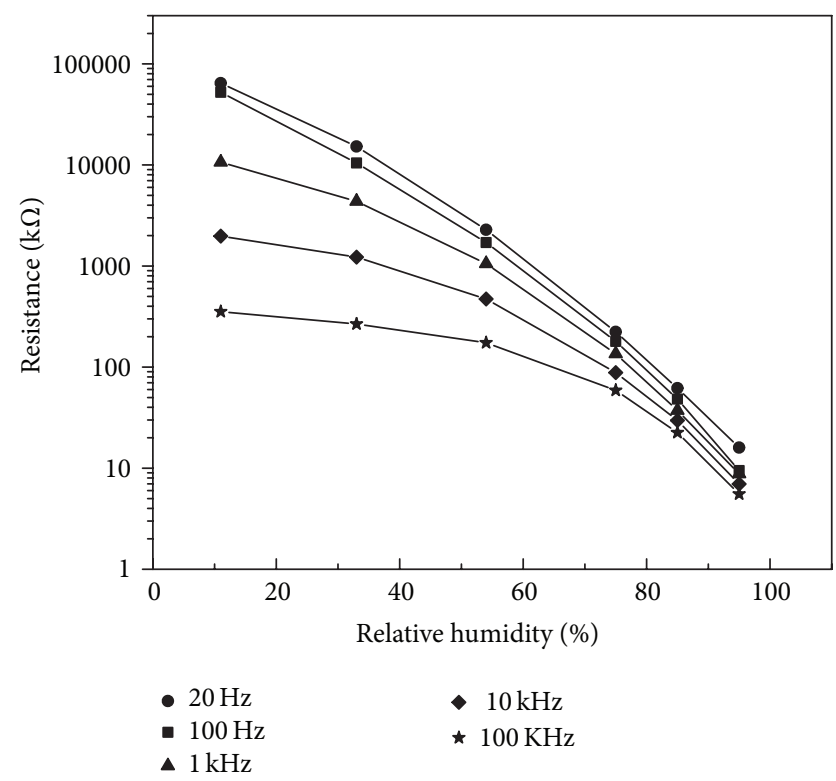

Figure 5: Resistance versus $\mathrm{RH}$ plots of $10 \mathrm{~mol} \% \mathrm{La}_{2} \mathrm{O}_{3}$ doped $\mathrm{CeO}_{2}$ nanopowders sensor at various frequencies.

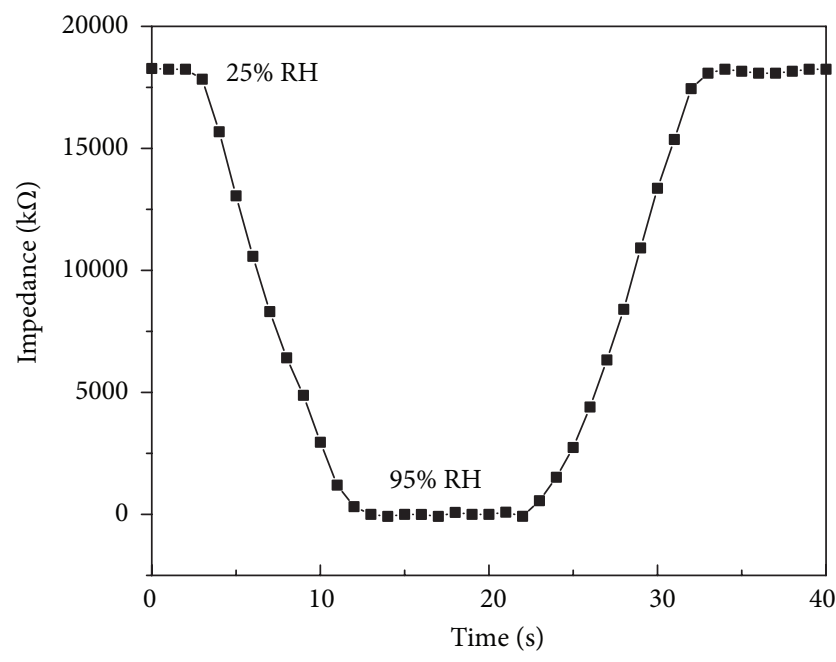

FIgURE 6: Response and recovery characteristics of $10 \mathrm{~mol} \% \mathrm{La}_{2} \mathrm{O}_{3}$ doped $\mathrm{CeO}_{2}$ nanopowders sensor measured at $100 \mathrm{~Hz}$.

Figure 5 shows the resistance variation of $10 \mathrm{LC}$ as a function of relative humidity $(\mathrm{RH})$ measured at room temperature with various frequencies. Obviously, the humidity dependences of the impedance of the sensor are influenced by the frequency and remarkably decreased at low frequency range (less than $100 \mathrm{~Hz}$ ). It can be seen from the figure, at low frequency region, that the impedance of the sensor varied five orders of magnitude with the relative humidity changing from $11 \%$ to $95 \%$. As a comparison between the humidity sensitivity of $10 \mathrm{LC}$ at high and low frequencies, the best sensitivity of the impedance versus $\mathrm{RH}$ curve appears at $100 \mathrm{~Hz}$ which shows higher sensing properties, better linear relation of resistance versus $\mathrm{RH}$, and larger impedance dropping. In the case of high frequencies $(10 \mathrm{KHz})$, however, the situation is just the reverse. In order to gain high $\mathrm{RH}$ sensitivity, therefore, the appropriate frequency should be fixed at $100 \mathrm{~Hz}$. This fact can be attributed to the mechanism of depletion type adsorption of semiconductor materials. As the carrier, for pure $\mathrm{CeO}_{2}$ humidity sensor, electrons have a significant role in the conduction process. Based on the Akubuiro study [17], the addition of low valent cation dopants results in decreasing the concentration of electrons, which implies that conductivity declines and impedance increases.

Response and recovery time are two important features to characterize the performance of humidity sensor. The time taken by a sensor to attain $90 \%$ to the total impedance change in the case of adsorption process and desorption process is defined as the response time and recovery time, respectively. Based on the results mentioned above, the response and recovery characteristics of $10 \mathrm{LC}$ at $100 \mathrm{~Hz}$ were investigated at room temperature, as shown in Figure 6. The sensor was transferred from laboratory atmosphere $(25 \% \mathrm{RH})$ to target chamber $(95 \% \mathrm{RH})$ to test the response time and then transferred back to investigate the recovery characteristic. As shown in Figure 6, the response and recovery time of the humidity sensor is $12 \mathrm{~s}$ and $13 \mathrm{~s}$, respectively. Such results indicate that the sensor made from $10 \mathrm{LC}$ has rapid response and recovery characteristics.

The hysteresis loop of the $10 \mathrm{LC}$ for adsorption and desorption behavior was measured in the whole humidity range at $100 \mathrm{~Hz}$ and room temperature, as represented in Figure 7. The humidification process is the black squares in the figure which was measured from low to high $\mathrm{RH}$, while the desiccation process is the write squares which was measured in the opposite direction. As can be seen from the figure, the sensor exhibits narrow hysteresis loop in the humidity range from $11 \%$ to $95 \% \mathrm{RH}$, and the maximum humidity hysteresis is about $6 \% \mathrm{RH}$. The narrow hysteresis loop indicates the facility of the humidification and desiccation process of water molecules.

Unfortunately, to the best of our knowledge, data on humidity sensing of $\mathrm{La}_{2} \mathrm{O}_{3}$ doping $\mathrm{CeO}_{2}$ is scarce in the literature. To explain the humidity sensitive properties of $10 \mathrm{LC}$, a possible mechanism was proposed. It is well known that the humidity sensing is closely related to chemisorption and physisorption processes of water molecules [18]. At low humidity, only a few water molecules are adsorbed by chemisorption mechanism, while several serial water layers will be formed at higher humidity by physisorption mechanism $[19,20]$. In our case, the great change in conductivity of the $10 \mathrm{LC}$ also relates to the adsorption of water molecules on the surface of $10 \mathrm{LC}$ film. In the case of low humidity, the sensor exhibits higher impedance which can be attributed to adsorption of a few water molecules on the surface of the film. The humid atmosphere on the surface is not continuous, which results in the electrolytic conduction being difficult. Based on [21, 22], the high local charge density and the strong electrostatic field caused by the tip, defects, and contracts of the powders can promote water dissociation to provide charge carriers. On the other hand, for high humidity, more and more water molecules physisorbed to form continuous water layer on the surface of film [23, 24]. A large amount of 


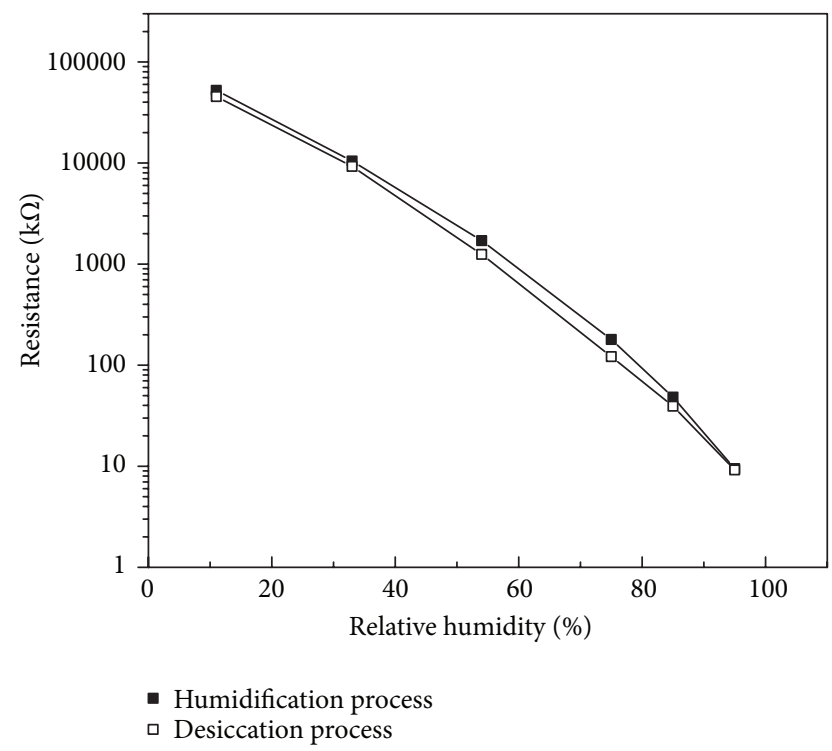

Figure 7: Hysteresis characteristics of $10 \mathrm{~mol} \% \mathrm{La}_{2} \mathrm{O}_{3}$ doped $\mathrm{CeO}_{2}$ humidity sensor.

$\mathrm{H}^{+}$decomposed from water molecules to be the dominant charged carriers and lead to large decrease of impedance. In addition, as mentioned above, the $10 \mathrm{~mol} \% \mathrm{La}_{2} \mathrm{O}_{3}$ doped $\mathrm{CeO}_{2}$ thin film has nanosized grains and high specific surface area. The nanoscale grain size leads to much more grain boundaries which result in more active sites available for water molecules to react [25]. The specific surface area of the particles also plays an important role in their conduction. The water molecules are easily absorbed on the surface of the sensors due to the large surface of nanomaterials, which can improve the response and recovery characteristics. Furthermore, the properties of humidity sensor which is fabricated by doped $\mathrm{CeO}_{2}$ are better than those of the bare one. This can be explained by two aspects as follows: for doped $\mathrm{CeO}_{2}$, the adsorption capacity of water molecular is larger than that of the undoped one due to the higher content of adsorption oxygen; on the other hand, the electrons will be depleted as the $\mathrm{La}^{3+}$ substitute the site of $\mathrm{Ce}^{4+}$. Thus, the electronic conductivity of the humidity sensor decreases.

\section{Conclusions}

Humidity sensing properties of $10 \mathrm{~mol} \% \mathrm{La}_{2} \mathrm{O}_{3}$ doped $\mathrm{CeO}_{2}$ prepared via hydrothermal method were investigated at different frequencies. It was found that the sensor at $100 \mathrm{~Hz}$ shows a high sensitivity, narrow hysteresis loop, and rapid response and recovery in the humidity range of $11 \% \sim 95 \% \mathrm{RH}$. The maximum humidity hysteresis is about $6 \% \mathrm{RH}$, and the response and recovery time of this thin film is 12 and $13 \mathrm{~s}$, respectively. Furthermore, the studies about $\mathrm{La}_{2} \mathrm{O}_{3}$ doped $\mathrm{CeO}_{2}$ with different content and different surfactants are in progress, which will be published elsewhere.

\section{Conflict of Interests}

The authors declare that there is no conflict of interests regarding the publication of this paper.

\section{Acknowledgment}

This work was supported by the National Natural Science Foundation of China under Grant no. 11347167.

\section{References}

[1] Z. M. Rittersma, "Recent achievements in miniaturised humidity sensors-a review of transduction techniques," Sensors and Actuators A, vol. 96, no. 2-3, pp. 196-210, 2002.

[2] S. Yin, G. Wang, and H. Karimi, "Data-driven design of robust fault detection system for wind turbines," Mechatronics, 2013.

[3] S. Yin, H. Luo, and S. Ding, "Real-time implementation of faulttolerant control systems with performance optimization," IEEE Transactions on Industrial Electronics, vol. 61, no. 5, pp. 24022411, 2014.

[4] E. Traversa, "Ceramic sensors for humidity detection: the stateof-the-art and future developments," Sensors and Actuators B, vol. 23, no. 2-3, pp. 135-156, 1995.

[5] E. B. Várhegyi, I. V. Perczel, J. Gerblinger, M. Fleischer, H. Meixner, and J. Giber, "Auger and SIMS study of segregation and corrosion behaviour of some semiconducting oxide gas-sensor materials," Sensors and Actuators B, vol. 19, no. 1-3, pp. 569-572, 1994.

[6] H. X. Li, Z. M. Shi, and H. W. Liu, "Humidity sensing properties of $\mathrm{La}^{3+} / \mathrm{Ce}^{3+}$-doped $\mathrm{TiO}_{2}-20$ wt. $\% \mathrm{SnO}_{2}$ thin films derived from sol-gel method," Journal of Rare Earths, vol. 28, no. 1, pp. 123$127,2010$.

[7] Y. Shimizu, H. Okada, and H. Arai, "Application of $\mathrm{La}_{2} \mathrm{O}_{3}-\mathrm{TiO}_{2}$ porous glass-ceramic system to a humidity sensor," Journal of the Ceramic Society of Japan, vol. 95, no. 7, pp. 726-731, 1987.

[8] M. Anbia and S. E. M. Fard, "Humidity sensing properties of Cedoped nanoporous $\mathrm{ZnO}$ thin film prepared by sol-gel method," Journal of Rare Earths, vol. 30, no. 1, pp. 38-42, 2012.

[9] C. J. Wang, W. Huang, Y. Wang et al., "Synthesis of monodispersed $\mathrm{La}_{2} \mathrm{Ce}_{2} \mathrm{O}_{7}$ nanocrystals via hydrothermal method: a study of crystal growth and sintering behavior," International Journal of Refractory Metals and Hard Materials, vol. 31, pp. 242246, 2012.

[10] H. Y. Jin, N. Wang, L. Xu, and S. Hou, "Synthesis and conductivity of cerium oxide nanoparticles," Materials Letters, vol. 64, no. 11, pp. 1254-1256, 2010.

[11] S. Yin, S. X. Ding, A. H. A. Sari, and H. Hao, "Data-driven monitoring for stochastic systems and its application on batch process," International Journal of Systems Science. Principles and Applications of Systems and Integration, vol. 44, no. 7, pp. 13661376, 2013.

[12] S. Brunauer, P. H. Emmett, and E. Teller, "Adsorption of gases in multimolecular layers," Journal of the American Chemical Society, vol. 60, no. 2, pp. 309-319, 1938.

[13] S. Yin, S. Ding, A. Haghani, H. Hao, and P. Zhang, "A comparison study of bacis datadriven fault diagnosis and process monitoring methods on the benchmark Tennessee Eastman process," Journal of Process Control, vol. 22, no. 9, pp. 1567-1581, 2012. 
[14] S. Patil, S. Seal, Y. Guo, A. Schulte, and J. Norwood, "Role of trivalent la and $\mathrm{Nd}$ dopants in lattice distortion and oxygen vacancy generation in cerium oxide nanoparticles," Applied Physics Letters, vol. 88, no. 24, Article ID 243110, 2006.

[15] Z. Xu, S. He, L. He, R. Mu, G. Huang, and X. Cao, "Novel thermal barrier coatings based on $\mathrm{La}_{2}\left(\mathrm{Zr}_{0.7} \mathrm{Ce}_{0.3}\right)_{2} \mathrm{O}_{7} / 8 \mathrm{YSZ}$ doubleceramic-layer systems deposited by electron beam physical vapor deposition," Journal of Alloys and Compounds, vol. 509, no. 11, pp. 4273-4283, 2011.

[16] C. W. Kuo, Y. H. Lee, K. Z. Fung, and M. C. Wang, "Effect of $\mathrm{Y}_{2} \mathrm{O}_{3}$ addition on the phase transition and growth of $\mathrm{YSZ}$ nanocrystallites prepared by a sol-gel process," Journal of NonCrystalline Solids, vol. 351, no. 4, pp. 304-311, 2005.

[17] M. Su, J. Wang, and Y. Hao, "Development of $\mathrm{Y}^{3+}$ and $\mathrm{Mg}^{2+}$ doped zirconia thick film humidity sensors," Materials Chemistry and Physics, vol. 126, no. 1-2, pp. 31-35, 2011.

[18] B. M. Kulwicki, "Humidity sensors," Journal of the American Ceramic Society, vol. 74, no. 4, pp. 697-708, 1991.

[19] W. M. Qu and W. Wlodarski, "A thin-film sensing element for ozone, humidity and temperature," Sensors and Actuators B, vol. 64, no. 1-3, pp. 42-48, 2000.

[20] X. Zhao, X. Liu, S. Yin, and H. Li, "Improved results on stability of continuous-time switched positive linear systems," Automatica, 2013.

[21] R. Schaub, P. Thostrup, N. Lopez et al., "Oxygen vacancies as active sites for water dissociation on rutile $\mathrm{TiO}_{2}(110)$," Physical Review Letters, vol. 87, no. 26, Article ID 266104, 4 pages, 2001.

[22] X. Zhao, L. Zhang, P. Shi, and H. Karimi, "Robust control of continuous-time systems with state-dependent uncertainties and its application to electronic circuits," IEEE Transactions on Industrial Electronics, 2013.

[23] G. Casalbore-Miceli, M. J. Yang, N. Camaioni et al., "Investigations on the ion transport mechanism in conducting polymer films," Solid State Ionics, vol. 131, no. 3, pp. 311-321, 2000.

[24] X. Zhao, L. Zhang, P. Shi, and M. Liu, "Stability of switched positive linear systems with average dwell time switching," Automatica, vol. 48, no. 6, pp. 1132-1137, 2012.

[25] X. Zhao, L. Zhang, P. Shi, and M. Liu, "Stability and stabilization of switched linear systems with mode-dependent average dwell time," IEEE Transactions on Automatic Control, vol. 57, no. 7, pp. 1809-1815, 2012. 


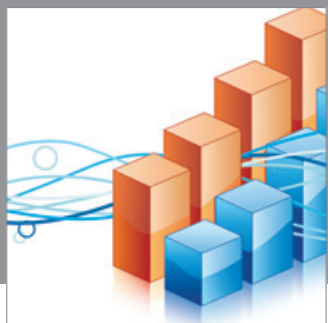

Advances in

Operations Research

mansans

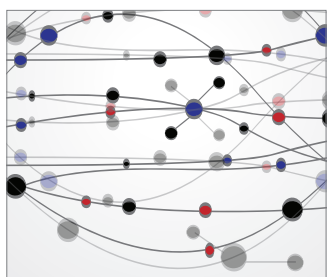

The Scientific World Journal
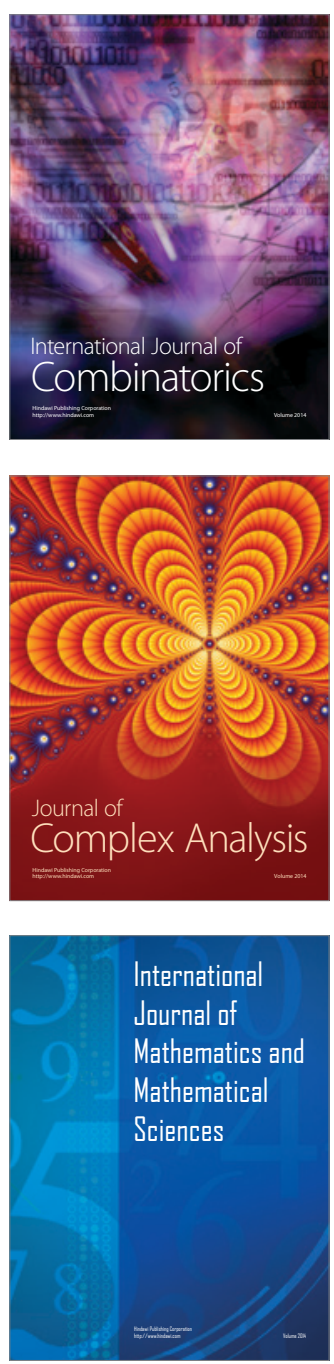
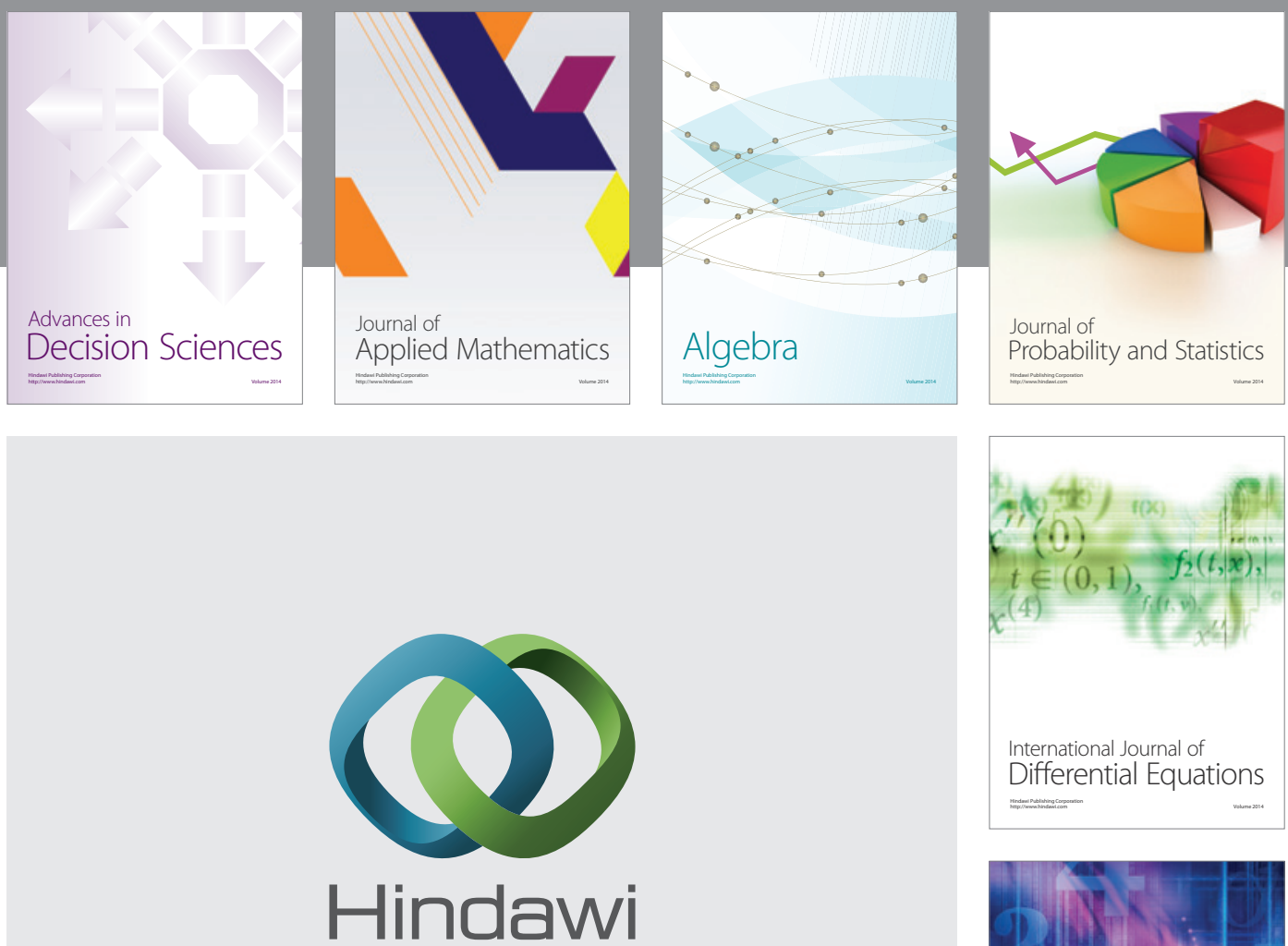

Submit your manuscripts at http://www.hindawi.com
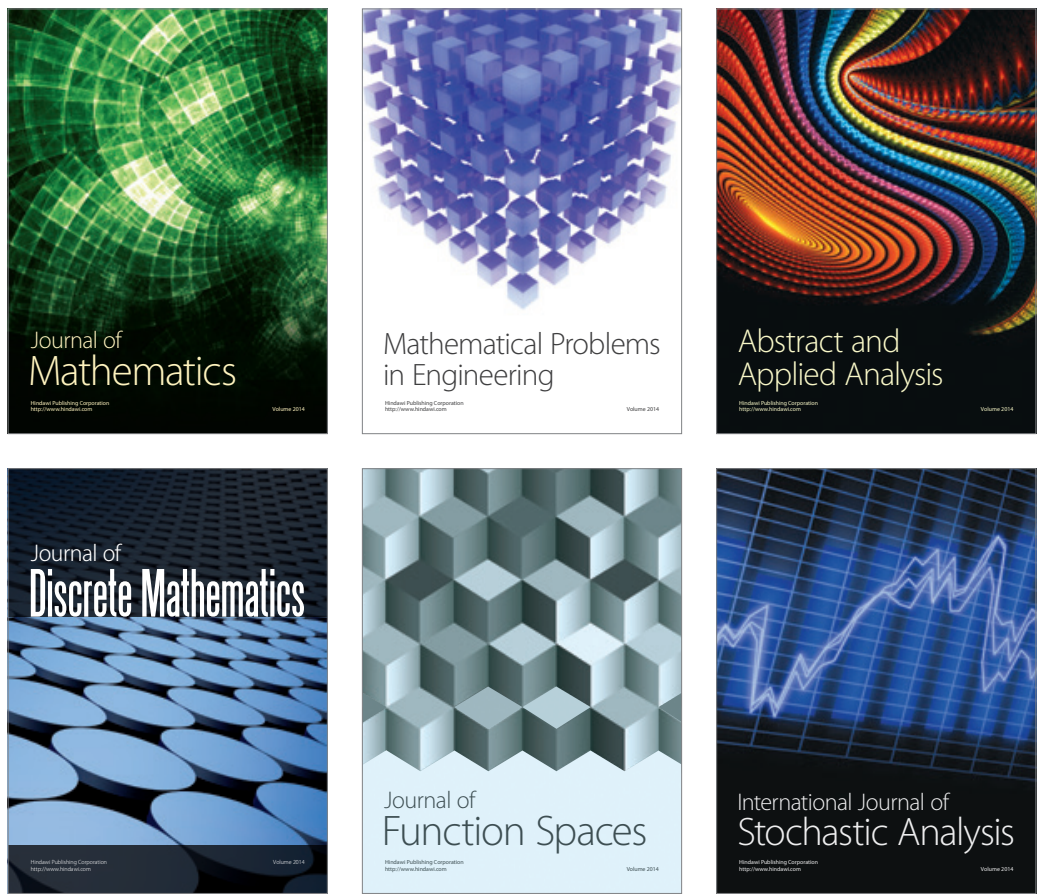

Journal of

Function Spaces

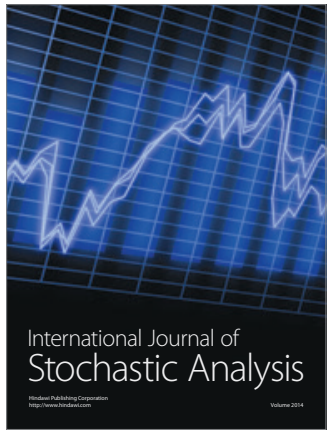

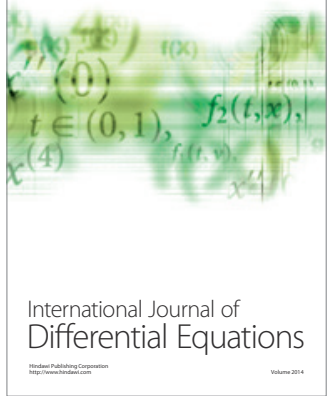
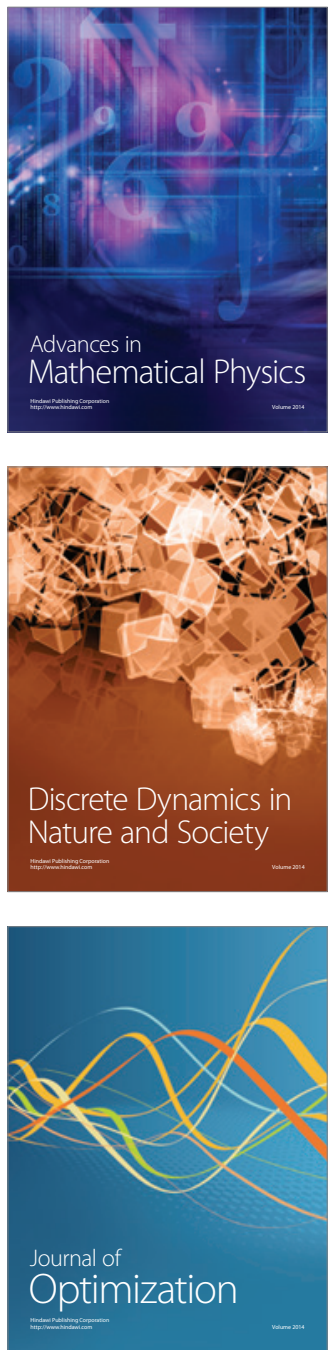